\title{
A Study of Serum Ferritin Activity in Metabolic Syndrome
}

\author{
Gaurav Sharma $^{1}$, Shivani Bansal ${ }^{2}$ \\ ${ }^{1}$ Senior Resident, Department of General Medicine, Ambedkar Hospital, New Delhi, India \\ ${ }^{2}$ Associate Professor, Department of General Medicine, Santosh Medical College and Hospitals, Ghaziabad, Uttar Pradesh, India
}

\begin{abstract}
Background: Patients with metabolic syndrome(MS) have above-average risk of developing atherosclerosis and cardiovascular disease. Inflammation plays a key role in the development of atherosclerosis. High levels of the acute phase reactants $C$ reactive protein (CRP) and ferritin have been reported to correlate with various components of MS. Patients and methods: The, ferritin, glucose, triglycerides, HDL-cholesterol and total cholesterol serum CRP concentrations of 25 controls and 100 cases were determined, together with relevant anthropometric parameters.. MS was diagnosed using the IDF criteria. Results: .Serum ferritin levels were higher among patients with triglyceride concentrations $>150 \mathrm{mg} / \mathrm{dl}$ than in those with lower levels (76.8 vs $40.1 \mathrm{ng} / \mathrm{ml} ; \mathrm{P}<0.001)$, and higher among those with fasting plasma glucose concentrations $\geq 110 \mathrm{mg} / \mathrm{dl}$ than in those with lower concentrations (75.7 vs $41.7 \mathrm{ng} / \mathrm{ml}$; $P=0.005)$. The number of MS criteria that were satisfied increased with ferritin levels. The serum ferritin value in controls was 38.66 \pm 14.48 and in cases it was 124.21 \pm 52.08 . Conclusions: Our results suggest that ferritin levels, which reflect the body's iron stores, are significantly and positively associated with the risk factors for metabolic syndrome. Moreover, two prospective studies indicate that blood ferritin levels may have a causal role in the development of metabolic syndrome. More prospective studies are needed to validate the finding.
\end{abstract}

Keywords: MS -Metabolic Syndrome, TG- triglyceride, CRP- C Reactive Protein, DM -Diabetes Mellitus, LDL- Low Density Lipoprotein

\section{Introduction}

The metabolic syndrome consists of a constellation of metabolic abnormalities that confer increased risk of cardiovascular disease (CVD) and diabetes mellitus (DM) [1]. The major features of the Metabolic Syndrome include central obesity, Hyper-triglyceridemia, low high-density lipoprotein (HDL) cholesterol, Hyperglycemia and Hypertension ${ }^{[1]}$.The metabolic syndrome now rears its head as one of the major public health issues of the $21^{\text {st }}$ century. It is currently prevalent in $20-25 \%$ of world's adult population. Serum ferritin levels measured have a direct correlation with the amount of iron stored in body ${ }^{[2]}$.Normal levels are 30$300 \mathrm{ng} / \mathrm{ml}$ for males \& 15-200ng/ml for females. Even moderately increased iron stores, represented by high ferritin concentrations, are associated with adverse health conditions, such as hypertension, dyslipidemia, elevated fasting insulin and blood glucose and central adiposity. Ferritin, an ubiquitous intracellular protein that is key in the regulation of iron homeostasis, is an accepted biomarker to evaluate body iron stores [3]. Evaluating if high serum ferritin is associated with the metabolic syndrome is relevant for both the clinician and the public health areas that focus on screening and prevention.

\section{Material and Methods}

The study has been conducted in Santosh Medical College, Ghaziabadduring a period of April 2013 to March 2014 as a case control study with number of casesbeing 100 and control 25.Total of 100 subjects of old or newly diagnosed metabolic syndrome on the basis of IDF Criteria for the diagnosis of metabolic syndrome. According to the guidelines:
- Waist Circumference: Waist circumference >90(M), $>80 \mathrm{~cm}(\mathrm{~F})$ in the South Asian individuals and two or more of the following,

- Hypertriglyceridemia: Triglycerides $>150 \mathrm{mg} / \mathrm{dl}$ or specific medication.

- Low HDL cholesterol: <40 mg/dl and <50 mg/dl, respectively for male and female or specific medication.

- Hypertension: Blood pressure $>130 \mathrm{mmHg}$ systolic or $>85 \mathrm{mmHg}$ diastolic or specific medication.

- Fasting plasma glucose $\geq 100 \mathrm{mg} / \mathrm{dl}$ or specific medication or previously diagnosed Type 2 diabetes.

\section{Exclusion criteria}

Anemia, haemochromatosis, hemolytic anemia.,Positive inflammatory markers, patient with gastrointestinal disease,thyroid disorder, oncological disease.

Detailed history and physical examination was done including anthropometry. Laboratory investigations like Complete blood count with peripheral blood smear, Blood glucose levels,Lipid profile, Kidney function test, Urine routine and microscopy, C- reactive protein, Serum ferritin were done.

Serum ferritin was estimated by micro ELISA using human ferritin enzyme immunoassay test with desirable levels in males are 30-300 ng/ml and females 15-200 ng/ml.

\section{Statistical Analysis}

All the parameters were analyzed by using software SPSS. Analysis of variance (ANOVA) has been used for comparing all the parameters. Case and Control were compared using Chi square test and Independent sample $\mathrm{t}$ test and p value was calculated. All the results are presented as means \pm Standard Mean Error (SEM). 


\section{International Journal of Science and Research (IJSR) \\ ISSN (Online): 2319-7064}

Index Copernicus Value (2013): 6.14 | Impact Factor (2015): 6.391

\section{Observation and Results}

A Case Control Study with 100 patients as cases and 25 patients as controls, which studied the activity of serum ferritin with each component of metabolic syndrome. 100\% cases had waist circumference $>90 \mathrm{cms}$, females $>80 \mathrm{cms}$.

Table 1: Triglyceride value in cases and controls

\begin{tabular}{|c|c|c|c|c|}
\hline $\begin{array}{c}\text { Total } \\
\text { Triglycerides }\end{array}$ & Controls & $\begin{array}{c}\text { Percent } \\
(\%)\end{array}$ & Cases & $\begin{array}{c}\text { Percent } \\
(\%)\end{array}$ \\
\hline$<150$ & 23 & 92 & 34 & 34 \\
\hline $151-200$ & 2 & 8 & 61 & 61 \\
\hline $201-250$ & 0 & 0 & 4 & 4 \\
\hline $251-300$ & 0 & 0 & 1 & 1 \\
\hline Total & 25 & 100 & 100 & 100 \\
\hline Mean \pm S.D & $128.72 \pm 26.14$ & & $162.09 \pm 26.78$ & \\
\hline
\end{tabular}

61 cases have LDL $<130 \mathrm{mg} / \mathrm{dl}$ and 35 between 131-200 $\mathrm{mg} / \mathrm{dl}$, 3 between 201-250 and $1>250 \mathrm{mg} / \mathrm{dl}$ whereas in controls 22 are $<130 \mathrm{mg} / \mathrm{dl}$ and 3 between 131-200 mg/dl

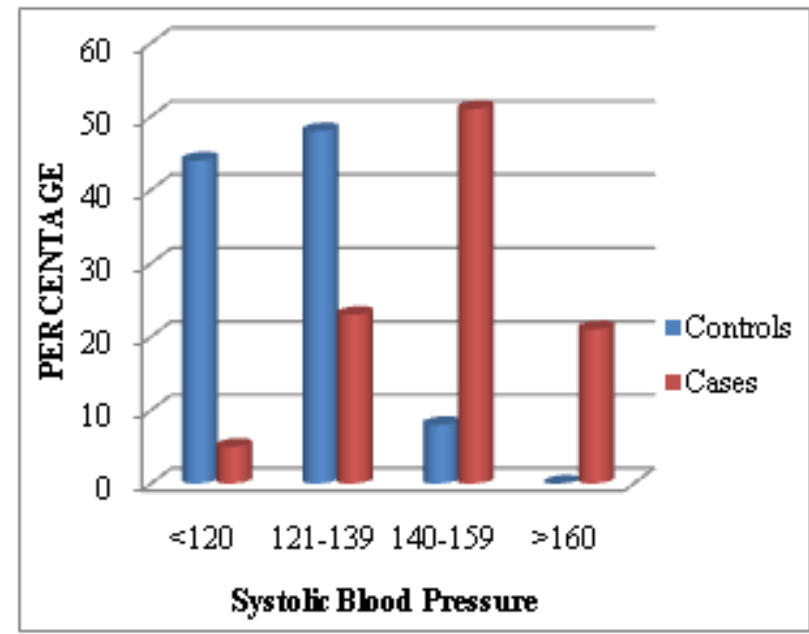

Graph 1: Systolic blood pressure in cases and controls

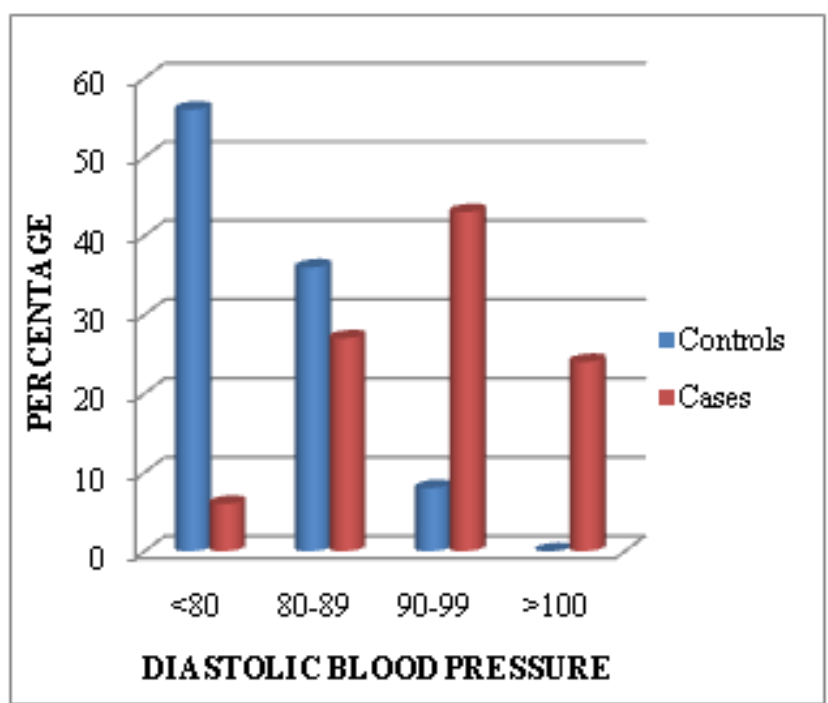

Graph 2: Diastolic blood pressure in cases and controls

The table shows $72 \%$ of controls were in their $3^{\text {rd }}$ decade of life have $34.62 \pm 10.19$ as mean serum ferritin as compare to $3 \%$ of cases in same age group have $77.93 \pm 15.42$ as mean serum ferritin while $8 \%$ of controls in $5^{\text {th }}$ decade of life have
$68.65 \pm 10.96$ as compare to $39 \%$ cases in same age group have $114.86 \pm 51.12$ as mean serum ferritin.

Table 2: Serum ferritin in cases and controls

\begin{tabular}{|c|c|c|c|c|}
\hline $\begin{array}{c}\text { Age } \\
\text { (years) }\end{array}$ & $\begin{array}{c}\text { Controls } \\
(\%)\end{array}$ & $\begin{array}{c}\text { Serum Ferritin } \\
(\text { Mean } \pm \text { S.D) }\end{array}$ & $\begin{array}{c}\text { Cases } \\
(\%)\end{array}$ & $\begin{array}{c}\text { Serum Ferritin } \\
(\text { Mean } \pm \text { S.D) }\end{array}$ \\
\hline $31-40$ & 72 & $34.62 \pm 10.19$ & 3 & $77.93 \pm 15.42$ \\
\hline $41-50$ & 20 & $41.20 \pm 15.97$ & 20 & $127.28 \pm 55.79$ \\
\hline $51-60$ & 8 & $68.65 \pm 10.96$ & 39 & $114.86 \pm 51.12$ \\
\hline $61-70$ & 0 & 0 & 36 & $127.74 \pm 48.94$ \\
\hline $71-80$ & 0 & 0 & 2 & $81.65 \pm 21.01$ \\
\hline Total & 100 & $38.66 \pm 14.48$ & 100 & $124.21 \pm 52.08$ \\
\hline
\end{tabular}

\section{Discussion}

The constellation of metabolic abnormalities including centrally distributed obesity, decreased high-density lipoprotein cholesterol (HDLC), elevated triglycerides, elevated blood pressure (BP) and hyperglycemia is known as the metabolic syndrome. There is increasing evidence that moderately elevated body iron stores, which are commonly found in genetic hemochromatosis, may be associated with adverse health effects.The present study was done to determine the association of serum ferritin in metabolic syndrome and to determine the levels of serum ferritin with components of metabolic syndrome. Since serum ferritin is an acute-phase reactant and may be elevated in the presence of inflammation ${ }^{[4]}$,to minimize this potential source of confounding by adjusting for CRP and by excluding those individuals with suspected inflammation, infection and liver disease.

Our finding corroborates with a study conducted by Park SK, Ryoo JH et al, who analyzed a cross sectional data and concluded that high serum ferritin level was independently associated with the prevalence of metabolic syndrome and its components ${ }^{[5]}$. Li Jiang, Wang $\mathrm{R}$ et al, also analyzed a cross sectional data and concluded that moderately elevated iron levels were associated with an increased prevalence of the metabolic syndrome and markers of insulin resistance ${ }^{[6]}$.

Several workers have postulated that oxidative stress and insulin resistance is the basic pathology in the development and progression of metabolic syndrome ${ }^{[7,8]}$. Iron is a transition metal, able to catalyze lipid peroxidation result in the formation of numerous free radicals that induce body tissue injury ${ }^{[9]}$.

There was positive relation between serum ferritin and triglycerides when mean serum ferritin of triglycerides (126.76 \pm 52.82$)$ was compared to mean serum ferritin of controls $(38.66 \pm 14.48)$, it was significant $(p=<0.001)$.The results of our study was in concordance with study conducted byLi B, Lin $\mathrm{W}$, Lin $\mathrm{N}$ et al which showed significant relation of serum ferritin with triglycerides. They demonstrated that hypertriglyceridemia and hypercholesterolemia causes a significant increase in serum ferritin levels. Halle $\mathrm{M}$ et al, also concluded that there is a positive correlation with triglyCentral obesity being the most important part of the metabolic syndrome and a definitive component of metabolic syndrome according to IDF criteria. In our study, we found out a significant relation between serum ferritin and central obesitycerides to serum ferritin 


\section{International Journal of Science and Research (IJSR) \\ ISSN (Online): 2319-7064 \\ Index Copernicus Value (2013): 6.14 | Impact Factor (2015): 6.391}

${ }^{[10]}$. Therefore the study has shown a significant relationship between serum ferritin and components of metabolic syndrome. Bozzini C, Girelli D et al also demonstrated that higher the level of serum ferritin, higher is the prevalence of metabolic syndrome ${ }^{[11]}$.

Biqiang Li, Wein Lin et al also concluded in their study that serum ferritin increases the risk of metabolic syndrome factors. They stated that higher the serum ferritin levels, higher the metabolic disorder severity and more frequent the metabolic syndrome incidence rate ${ }^{[12]}$.

Thus, our study indicated that serum ferritin may be a predictor for development of metabolic syndrome.

\section{Conclusion}

This study concludes that, the incidence of metabolic syndrome is increasing at a rapid rate in developing and developed countries. Our study and several other studies have shown that serum ferritin can be an important indicating marker of metabolic syndrome.

This study is based on IDF criteria for diagnosing metabolic syndrome, the advantages and benefits of using this definition is that it limits or restricts the use of blood investigations as central obesity being the most important component of this definition. IDF may be a more feasible, particular and cost effective approach in community set up. It was concluded that:

1) There is a positive association between serum ferritin and metabolic syndrome.

2) There is a positive correlation between individual components of metabolic syndrome with serum ferritin.

3) Serum ferritin levels increases with increasing number of components of the metabolic syndrome.

\section{References}

[1] Robert H Eckel. Chapter 242; the metabolic syndrome; page 1992, Harrison Principles of Internal Medicine $18^{\text {th }}$ edition, 2012.

[2] Powell LW, George DK, McDonnell SM, Kowdley KV. Diagnosis of hemochromatosis. Ann Intern Med; 1993; 129:925-931

[3] Cook JD, Lipschitz DA, Miles LE, Finch CA: Serum ferritin as a measure of iron stores in normal subjects. Am J ClinNutr 1974, 27:681-687.

[4] Gabay C, Kushner I. Acute-phase proteins and other systemic responses to inflammation. N Engl J Med; 1999; 340:448-454.

[5] Park SK, Ryoo JH et al. Association of serum ferritin and the development of metabolic syndrome in middle aged Korean men A 5 year follow up study. Diabetes Care; 2012; 35:2521-2526.

[6] Li Jiang, Wang R et al. Association between Serum Ferritin and Risk of Metabolic Syndrome in Chinese Adults: A Population Study. PLoS ONE; 2013; 8(9):e74168

[7] Eckel RH, Grundy SM, Zimmet PZ. The metabolic syndrome. Lancet; 2005; 365:1415-1428.
[8] Furukawa S, Fujita T, Shimabukuro M, et al. Increased oxidative stress in obesity and its impact on metabolic syndrome. J Clin Invest; 2004; 114:1752-1761.

[9] Wolff SP, et al. Diabetes mellitus and free radicals: free radicals, transition metals and oxidative stress in the aetiology of diabetes mellitus and complications. $\mathrm{Br}$ Med Bull; 1993; 49:642-652.

[10] Halle M, Knig D, Berg A, Keul J, Baumstark M. Relationship of serum ferritin concentrations with metabolic cardiovascular risk factors in men without evidence for coronary artery disease. Atherosclerosis; 1997; 128:235-240.

[11] Bozzini C, Girelli D, Olivieri O, Martinelli N, Bassi A et al. Prevalance of body iron excess in the metabolic syndrome. Diabetes care; 2005; 28:2061-2063.

[12] Li B, Lin W, Lin N, Dong X, Liu L. Study of the correlation between Serum Ferritin levels and the aggregation of metabolic disorders in non-diabetic elderly patients. Experimental \& Therapeutic Medicine; 2014; 7:1671-1676. 